\title{
Food aroma affects bite size
}

\author{
René A de Wijk ${ }^{1,2^{*}}$, Ilse A Polet ${ }^{1,2}$, Wilbert Boek ${ }^{3}$, Saskia Coenraad ${ }^{3}$ and Johannes HF Bult ${ }^{1,4}$
}

\begin{abstract}
Background: To evaluate the effect of food aroma on bite size, a semisolid vanilla custard dessert was delivered repeatedly into the mouth of test subjects using a pump while various concentrations of cream aroma were presented retronasally to the nose. Termination of the pump, which determined bite size, was controlled by the subject via a push button. Over 30 trials with 10 subjects, the custard was presented randomly either without an aroma, or with aromas presented below or near the detection threshold.
\end{abstract}

Results: Results for ten subjects (four females and six males), aged between 26 and 50 years, indicated that aroma intensity affected the size of the corresponding bite as well as that of subsequent bites. Higher aroma intensities resulted in significantly smaller sizes.

Conclusions: These results suggest that bite size control during eating is a highly dynamic process affected by the sensations experienced during the current and previous bites.

\section{Background}

Eating and drinking serve to transfer food and drink from the mouth towards the throat before they enter the stomach and intestines. Before they enter these parts of the digestive system, foods are 'predigested'; that is, broken down in the mouth via mechanical and enzymatic degradation. The resulting fragments are mixed with saliva into a consistent bolus that is safe to swallow. The amount of food that is processed each time in the mouth (the bite size) is highly variable between consumers [1], between foods, and even within the same food when a single property such as viscosity is varied [2]. Solid foods that require more breaking down in the mouth typically result in smaller bite sizes than semisolid foods and liquids. Smaller bite sizes are known to elicit weaker food sensations [3], lower flavor release [4] and more satiation $[5,6]$. Furthermore, bite sizes tend to be smaller for unfamiliar foods and foods that are liked less [7]. Finally, bite sizes become smaller as the consumer becomes satiated [2]. These results suggest that bite size is actively regulated during eating in response to sensory and/or digestive factors.

Insight into the dynamics of bite size regulation may not only be relevant from a theoretical point of view, but may also assist in the development of foods that are

\footnotetext{
*Correspondence: rene.dewijk@wur.nl

${ }^{1}$ Top Institute Food and Nutrition, Wageningen, The Netherlands
}

Full list of author information is available at the end of the article more satiating and are therefore consumed in smaller quantities. Given this objective, the use of aromas to affect bite size is particularly interesting since these can be manipulated without raising the caloric content of the food. We hypothesize that aroma exposure during eating affects bite size for the following two reasons. Firstly, perceived flavor intensity may be regulated adaptively by bite size to maintain moderate intensities; increasing flavor intensity would then elicit smaller bite sizes. Secondly, aromas that signal a creamy, fat-containing dairy product increase the perception of the product's creaminess and thickness on a bite-by-bite basis [8]. By presenting these aromas during a bite, the increase in the perceived creaminess and thickness is also expected to affect bite size. We hypothesized that higher aroma intensities would lead to smaller bite sizes and vice versa.

The present study investigated the dynamics of bite size control by presenting subjects with a series of bites of a semisolid food where the aroma released during oral processing varied from bite to bite. The results indicate whether aroma release can affect the current bite and/or subsequent bites. The formulation of an aroma or taste stimulus will not only affect the evaluation of that stimulus, but also the evaluation of subsequent stimuli $[9,10]$. If aromas affect bite size, these effects may, therefore, persist over multiple bites. To evaluate the effects of current and previous aroma stimulation
Ciomed Central

(ㄷ) 2012 De Wijk et al; licensee BioMed Central Ltd. This is an open access article distributed under the terms of the Creative Commons Attribution License (http://creativecommons.org/licenses/by/2.0), which permits unrestricted use, distribution, and reproduction in any medium, provided the original work is properly cited. 
independently, we randomized and balanced subsequent aroma conditions $[11,12]$.

Aroma variations in foods often affect other food properties as well due to physicochemical interactions, such as the food's viscosity [13-15]. Because these effects would hamper the interpretation of the results of this study, an olfactometer was used to present aromas independently of the food. The aroma was presented retronasally so that it follows the same route to the olfactory epithelium as aromas released by the food would follow during normal consumption $[8,16]$.

\section{Results}

Bite size averaged $5.95 \mathrm{ml}( \pm 2.1 \mathrm{SD})$ and did not vary consistently with bite number, indicating that intakedependent processes such as satiation are not apparent during consumption (see Figure 1, gray bars). However, inspection of individual results showed considerable variation in bite sizes from one bite to the next (see Figure 1, black bars).

The results indicate that bite size decreases with aroma concentration, that is, the high aroma concentration resulted in significantly smaller bite sizes than the stimuli without aroma $(\mathrm{F}(1,9)=5.5, P<0.05)$. The low aroma concentration resulted in marginally smaller bite sizes than the stimuli without additional aroma $(\mathrm{F}(1,9)=$ 3.0, $P=0.11$ ) (see Figure 2, aroma condition of current bite $\mathrm{N}-1 \leq \mathrm{N} \leq 30$, where $\mathrm{N}$ is the current bite and $\mathrm{N}-1$ is the last bite). A similar effect was observed for the aroma condition of the previous bite (see Figure 2, aroma condition of bite $\mathrm{N}-1$ ), however this effect was too small to be significant. The size of a bite is also affected by the aroma condition of bite N-2 (second to last bite); if bite number N-2 has no aroma, the bite size of bite number $\mathrm{N}$ is smaller than when bite number $\mathrm{N}-2$ has a weak aroma $(\mathrm{F}(1,9)=27.1, P=0.01)$ or a strong aroma $(\mathrm{F}(1,9)=6.1, P=0.04)$ (see Figure 3 , aroma condition of bite $\mathrm{N}-2)$.

\section{Discussion}

Previous findings have demonstrated that bite sizes vary with how familiar the food is, and with its hedonic and textural properties. In addition the findings showed that smaller bite sizes are more satiating and that bite sizes become smaller as the consumer becomes more satiated. These studies indicate that bite size control is sensitive to general food properties as well as to the internal state of the consumer.

The results of the present study demonstrate that bite size control is sensitive to food sensations (aroma intensity) that vary from bite to bite, even at aroma concentrations below or near the perception threshold. In line with our hypothesis, the bite size was smallest for the highest aroma intensity. This result suggests a rapid feedback mechanism in which the aroma is perceived during the filling of the mouth, and where the outcome of this evaluation is used to terminate the bite. This feedback loop takes no more than a few seconds.

A likely reason for reducing the bite size when sensations become more intense is that consumers self-regulate their sensations via bite size, whereby weak sensations are intensified via larger bite sizes and stronger sensations are weakened via smaller bite sizes. This hypothesis is supported by other recent results from our laboratory that demonstrated that higher salt intensities were associated with smaller bite sizes in soups that were designed to be

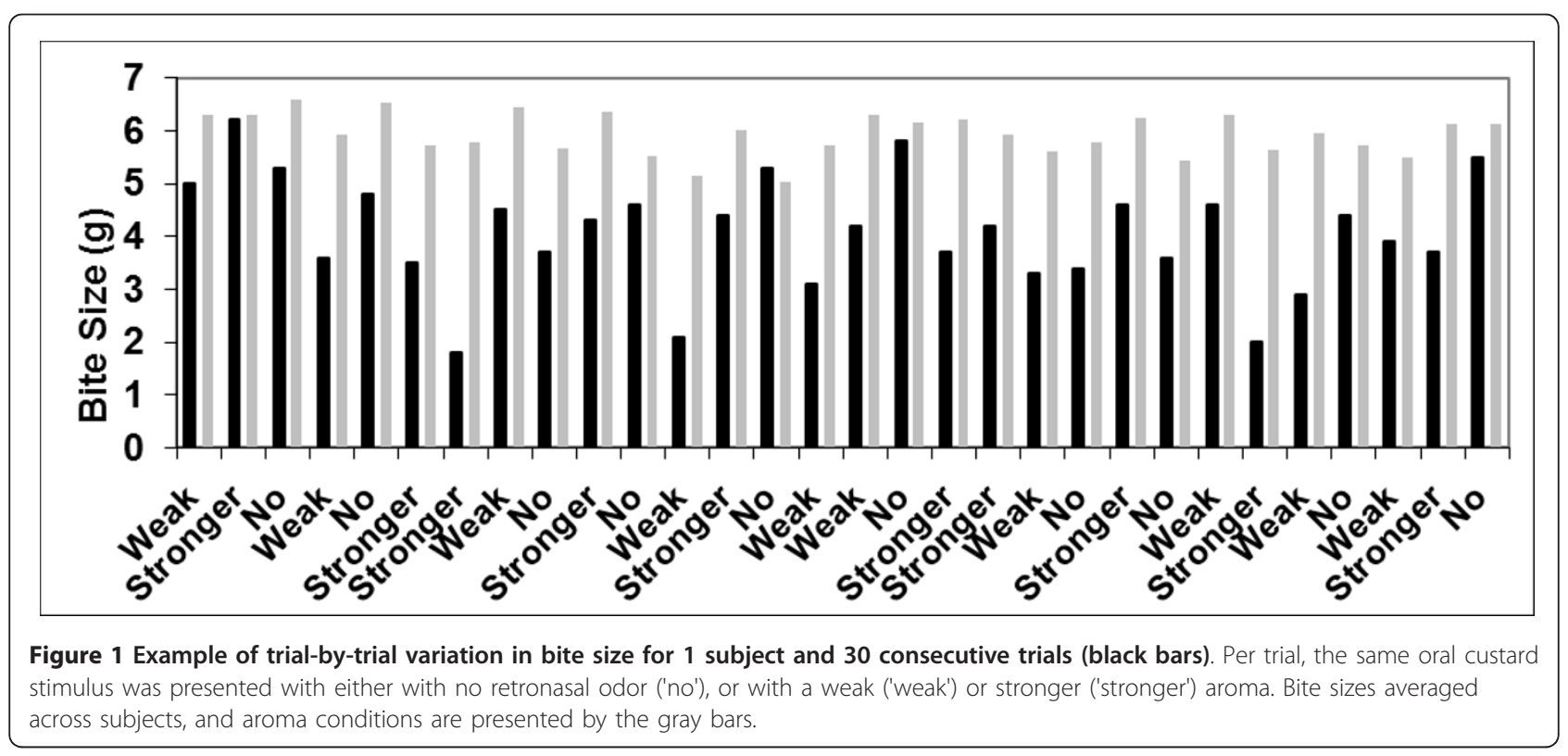




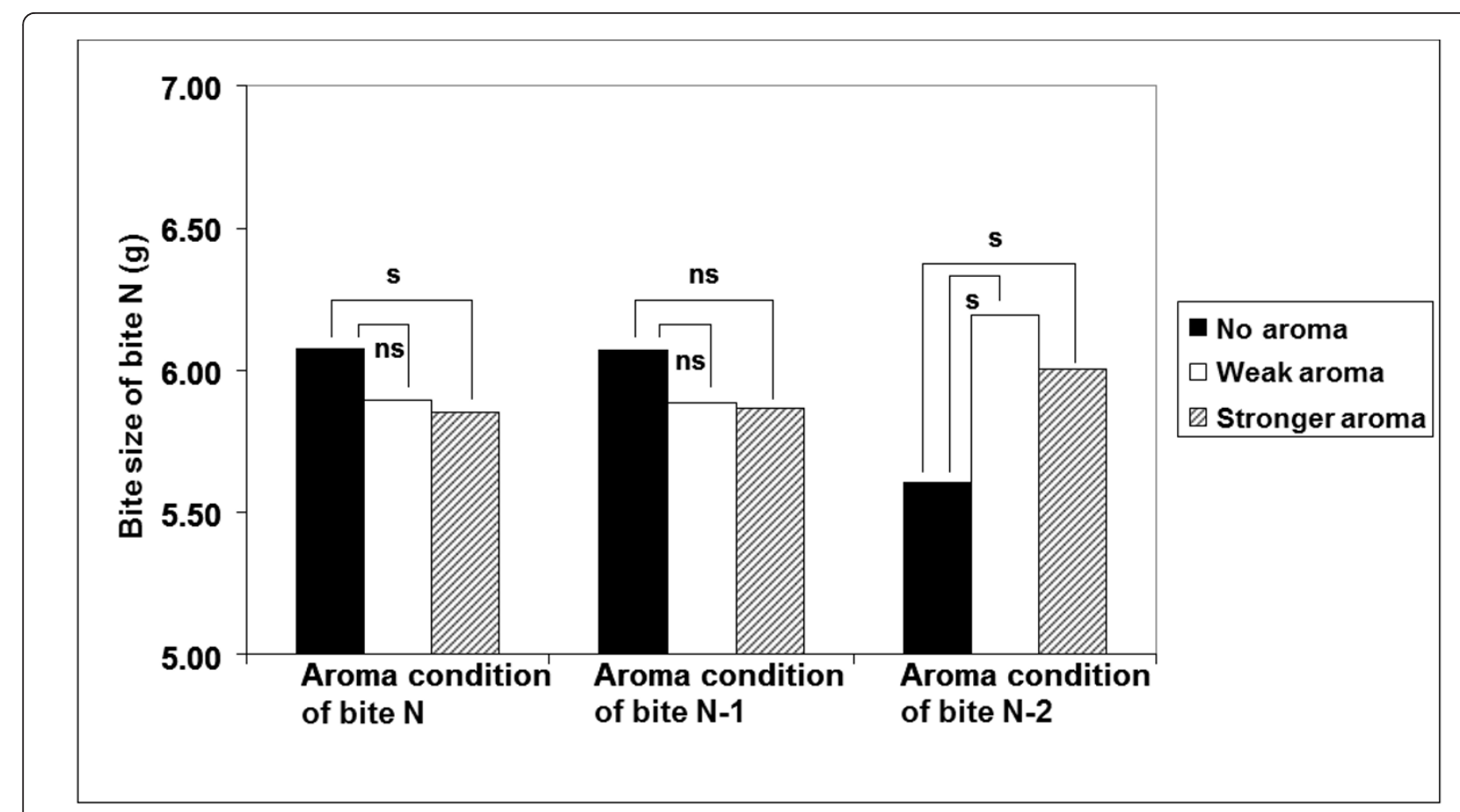

Figure 2 Bite size as a function of aroma condition of current bite (left), last bite (middle) and second to last bite (right). Significances of the differences are indicated in the figure ( $S=$ significant, $P<0.05$; NS $=$ non-significant).

equally pleasant to eat [17], The bite size reduction caused by taste was approximately $5 \%$, that is, it was similar to the reduction found in the present study for smell. The intensity effect on bite size may not be limited to smell and taste but may also extend to texture sensations, as demonstrated by the fact that thicker textures resulted in smaller bite sizes than thinner ones [2].
Alternatively, stronger cream aromas make the custard seem thicker and more creamy (see [8]), and therefore possibly higher in calories.

The effect of aroma on bite size is not limited to the corresponding bite but also extends to subsequent bites. In fact, the bite size was most affected by the aroma conditions of the second-to-last bite. What is even more

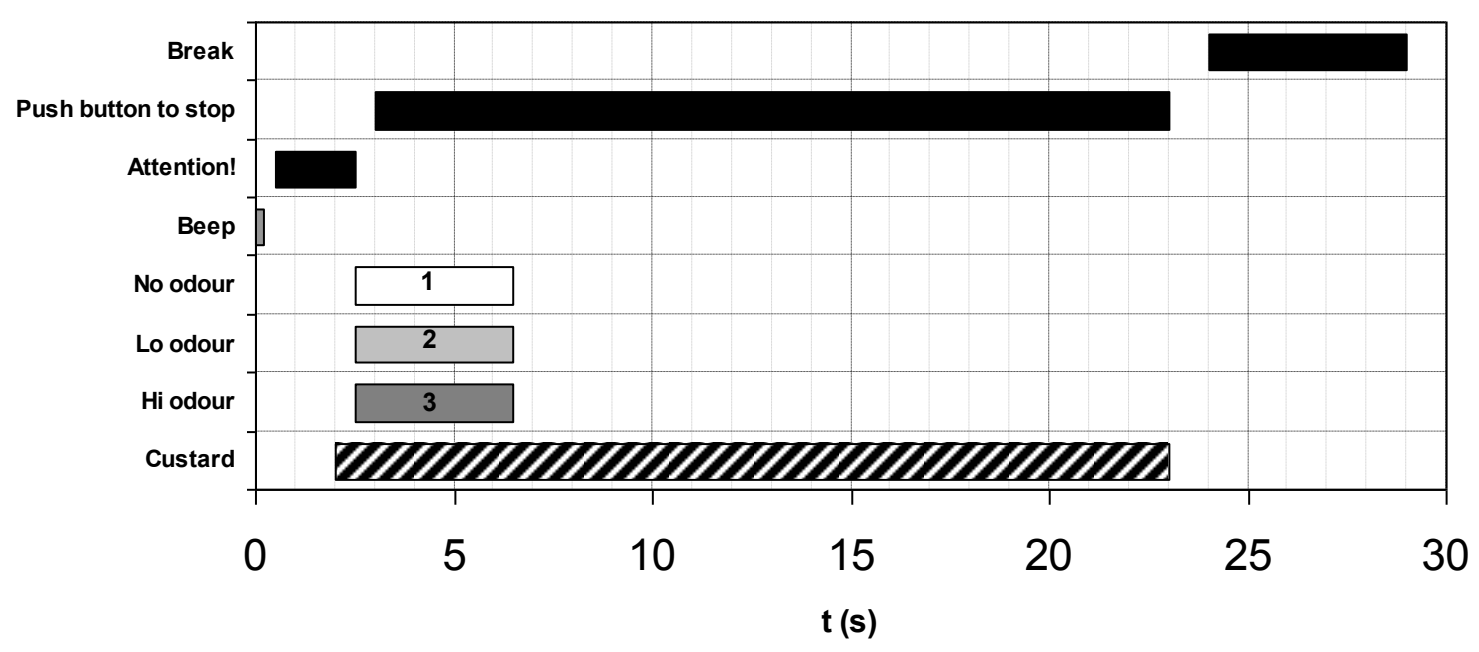

Figure 3 Sequence of events in each $30 \mathrm{~s}$ trial as function of time. Custard presentation at $60 \mathrm{~g} / \mathrm{min}$ (striped bar, maximum $21 \mathrm{~s}$, subjectterminated), screen instructions (black bars), a $400 \mathrm{~Hz}$ beep (gray bar) and one of three aroma conditions (no aroma (1), white bar; 10\% aroma concentration (weak) (2); light gray bar; 100\% aroma concentration (stronger) (3), dark gray bar). 
interesting is that the effect of aroma on bite size from this bite is the opposite of the effect observed for the corresponding bite. This study design is not able to provide explanations for this unexpected reversal, but it demonstrates that bite size control is a complex process. One possible explanation, which would require further investigation, is that food intake may be approximately stable over multiple bites, whereby deviations on individual bites are compensated by subsequent bites.

The reduction in bite size as a result of aroma is relatively small, but may be relevant in normal consumption if it is not compensated by larger numbers of bites, that is, when the meal size is also decreased. In that case a reduction of approximately $5 \%$ to $10 \%$ in intake, as found in the present study based on the single-bite results, is already considerable. An additional study with normal eating is needed to verify this hypothesis.

The set up used in this study, that is, the combination of olfactometer and pump that was stopped by the subject, was developed specifically to investigate the effects of aroma on bite size. In normal eating, bite size is typically more or less determined by the utensil used. A spoon is used to eat a liquid or semisolid food, and a fork is used to eat a solid. During one bite, there is virtually no opportunity to adjust the bite size based on food sensations. Instead, adjustment of intake may take place during subsequent bites, or in the total number of bites, as suggested by a recent study in our laboratory that demonstrated that soups with a high salt content were consumed in fewer bites than low salt soups [18].

Bite size control may not be the only mechanism for self-regulation of food intake. Other possible mechanisms include the way foods are processed in the mouth. Previous findings have demonstrated that the intensity of food sensations varied directly with the way foods are processed. For example, creaminess becomes more intense when the food is not only compressed between tongue and palate but is also sheared via lateral movements of the tongue along the palate [19]. Weaker sensations may elicit more elaborative oral movements than stronger ones. Similarly, foods eliciting weaker sensations may be processed in the mouth for a longer period of time than foods eliciting stronger sensations. To the best of our knowledge, such mechanisms have not yet been studied.

\section{Conclusions}

In summary, increasing the aroma intensity reduces the bite size. This result fits into a growing body of literature that suggests that bite size control plays an important role in the self-regulation of food sensations.

\section{Methods}

\section{Subjects}

Ten subjects (six male, four female), aged between 26 and 50 years and with a normal sense of smell, participated in the experiment. Their average age was 36 years old $(\mathrm{SD}=9)$, and their body mass index (BMI) ranged from 22 to $30.0 \mathrm{~kg} / \mathrm{m}^{2}$. The subjects did not have an aversion to vanilla custard dessert. All subjects had participated in earlier sensory experiments but were unaware of the aim of the present study. All subjects were paid for participation and gave informed consent. The research was approved by the MedicalEthical Review Committee in Wageningen (File no. NL16918.081.07).

\section{Food and food presentation}

A commercially available fresh vanilla custard dessert (Friesche Vlag Halfvolle Vanille vla, 1.5\% w/w fat) was used as the test food. A peristaltic pump (HR flow inducer, MHRE 200; Watson-Marlow, Falmouth, UK) with a silicon tube (length $1.5 \mathrm{~m}$, inner diameter $10 \mathrm{~mm}$ ) was used to deliver the product into the subject's mouth. The pump flow rate was fixed to control the eating rate (60 $\mathrm{g} / \mathrm{min})$. Each delivery of food was stopped by the subject via a push button, enabling the subject to control the size of the bite. Bite size was calculated by measuring the difference in weight of the food before and after each bite using a computerized weighing scale. Subjects were not aware of the weighing and received no visual cues as to the amount of food ingested.

\section{Aroma and aroma presentation}

At the beginning of each day of experimentation, $5 \mathrm{~g}$ of commercially available cream aroma (Butter Buds Asia; Butter Buds, Racine, WI, USA) was dissolved in $1000 \mathrm{~g}$ of demineralized water and shaken until fully dissolved. Aromas were presented via an apparatus (Olfactometer OM2s; Burghart Instruments, Wedel, Germany) that allowed application of chemical stimuli without causing concomitant mechanical or thermal sensations [20]. This was achieved by embedding a natural cream aroma in a constantly flowing air stream $(8 \mathrm{l} / \mathrm{min})$. The air saturation chamber of the olfactometer was filled with $10 \mathrm{ml}$ of fresh aroma solution before each experimental session. The 'air'/'saturated odorized air' dilution of odorous stimuli was set to $16: 1$ for the weaker and stronger concentration. The weaker concentration had $10 \%$ of the strength of the stronger concentration, and was produced by presenting the stronger concentration for a $100 \mathrm{~ms}$ burst once every second. The temperature and humidity of the air stream were kept constant $\left(36.5^{\circ} \mathrm{C}\right.$, $>80 \%$ relative humidity). The rise time of the odorant concentration was less than $20 \mathrm{~ms}$. 
The aromas were released into the epipharynx through a tube positioned under endoscopic control by a licensed doctor [21]. A tube of approximately $23 \mathrm{~cm}$ was cut from a sterile suction catheter made from soft polyvinyl chloride. This tube was placed inside the nose under endoscopic control so that the opening of the tube was at the level of the soft palate (approximately $8 \mathrm{~cm}$ from the naris). The other end of the tube was connected to the outlet of the olfactometer.

Food presentation, aroma presentation and screen instructions were controlled by a single computing unit running dedicated software written in Delphi [22]. The order of aroma/food combinations was randomized per subject, while keeping combinations of consecutive aroma conditions balanced.

\section{Procedure}

Subjects were seated in an upright position in a dentist's chair. The outlets of the olfactometer and pump were positioned in front of the mouth of the subject and mounted on a stable support. This allowed for a comfortable application of the mouthpeices and nosepieces. Food/ aroma presentations were repeated every $30 \mathrm{~s}$. All trials consisted of a $400 \mathrm{~Hz}$ auditory warning signal, screen instructions, ad lib custard presentation and concurrent retronasal aroma presentations at $0 \%, 10 \%$ or $100 \%$ of the concentrations prepared by the olfactometer. A delay of $500 \mathrm{~ms}$ between custard and aroma presentations was chosen to mimic the normal eating situation, where there is also a brief delay between the moment food enters the mouth and the start of aroma release (see Figure 3). The aroma concentrations were selected so that the strongest concentration was detected by approximately $50 \%$ of the subjects (that is, a perithreshold concentration), whereas the weakest concentration was virtually never detected (that is, a subthreshold concentration). The choice of these concentrations was based on a previous study that demonstrated that sensory integration of food and aromas takes place for relatively weak aromas that do not stand out relative to the flavor of the product [8].

Each of the three aroma concentrations (no aroma/ low/high) was presented ten times to each subject in combination with the same oral stimulus. Hence, each subject was presented with 30 test stimuli, preceded by 3 practice stimuli that were not included in the analysis. Each session lasted $16.5 \mathrm{~min}$. To balance consecutive aroma conditions, the 30 stimuli were presented in 10 blocks of 3 stimuli with different aroma concentrations in randomized order within each block. This design also minimizes the influence of day-to-day fluctuations in the subject's nutritional baseline, and of distractions or ambient factors that may interfere with the effect being measured, namely that of aroma on bite size. The total custard consumption did not exceed that of an average dessert. Analysis of how the bite size varies with the number of bites taken indicates whether processes related to bite number, such as satiety, take place.

\section{Statistical analysis}

The effects of aroma concentrations on bite size were analyzed using repeated measures analysis of variance (ANOVA; SPSS, SPSS Inc., Chicago, Il, USA) and intrasubject post hoc contrast tests to verify the significant effects of the aroma on the bite size of the current bite, and of the two subsequent bites. Data are presented as mean averages.

\section{Acknowledgements}

We thank Dr Mari Wigham for her help with editing the manuscript.

\section{Author details}

${ }^{1}$ Top Institute Food and Nutrition, Wageningen, The Netherlands. ${ }^{2}$ Food \& Biobased Research, Consumer Science \& Intelligent Systems, Wageningen, The Netherlands. ${ }^{3}$ Hospital 'De Gelderse Vallei', Ede, The Netherlands. ${ }^{4}$ Nizo Food Research, Ede, The Netherlands.

\section{Authors' contributions}

RAdW conceived the idea for the study and drafted the manuscript. JFHB developed the necessary hardware and software for the study IAP participated in the design of the study and carried out the statistical analysis. WB and SC set up the study protocol, conducted the study, and prepared the data for further analyses. All authors were involved in developing the first draft of the manuscript into the final version suitable for publication.

\section{Competing interests}

The authors declare that they have no competing interests.

Received: 4 July 2011 Accepted: 21 March 2012

Published: 21 March 2012

\section{References}

1. Prinz JF, de Wijk RA: Perceptual effects of ingested volume in semi-solid foods. J Sens Studies 2007, 22:273-280.

2. de Wijk RA, Zijlstra N, Mars M, de Graaf C, Prinz JF: The effects of food viscosity on bite size, bite effort and food intake. Physiol Behav 2008, 95:527-532.

3. de Wijk RA, Engelen L, Prinz JF, Weenen $H$ : The influence of bite size and multiple bites on oral texture sensations. J Sens Studies 2003, 18:423-435.

4. Linforth RST, Blissett A, Taylor AJ: Differences in the effect of bolus weight on flavor release into the breath between low-fat and high-fat products. J Agr Food Chem 2005, 53:7217-7221.

5. Weijzen PLG, Liem GD, Zandstra LH, de Graaf C: Sensory specific satiety and intake, The difference between nibble- and bar-size snacks. Appetite 2008, 50:435-442.

6. Zijlstra N, de Wijk RA, Mars M, MS, Stafleu A, de Graaf C: Effect of bite size and oral processing time of a semi-solid food on satiation". The American Journal of Clinical Nutrition, Am J Clinical Nutrition 2009, 90:269-275.

7. De Wijk RA, Prinz JF, Polet IA, van Doorn RM: Amount of ingested custard as affected by its color, smell, and texture. Physiol Behav 2004, 82:397-403.

8. Bult JHF, de Wijk RA, Hummel T: Investigations on multimodal sensory integration, texture, taste, and ortho- and retro nasal olfactory stimuli in concert. Neurosci Lett 2007, 411:6-10.

9. Lawless HT: A sequential contrast effect in odor perception. B Psychonomic Soc 1991, 29:317-319.

10. Schifferstein HNJ, Frijters JER: Contextual and sequential effects on judgements of sweetness intensity. Percept Psychophys 1992, 52:243-255.

11. Jesteadt W, Luce RD, Green DM: Sequential effects in judgments of loudness. J Exp Psychol Human 1977, 3:92-104. 
12. DeCarlo LT, Cross DV: Sequential effects in magnitude scaling: models and theory. J Exp Psychol Gen 1990, 119:375-396.

13. Nueslli J, Conde-Petit B, Trommsdorff UR, Escher F: Influence of starch flavour interactions on rheological properties of low concentration starch systems. Carbohyd Polym 1995, 28:167-170.

14. Escher F, Nuessli J, Conde-Petit B: Interactions of flavor compounds with starch in food processing. In Flavor Release. Edited by: Roberts DD, Taylor AJ. Washington DC, USA: American Chemical Society; 2000:230-245.

15. de Wijk RA, Rasing F, Wilkinson CL: Sensory flavor-texture interactions for custards. J Text Studies 2003, 34:131-146.

16. Ruijschop RM, Boelrijk AE, de Ru JA, de Graaf C, Westerterp-Plantenga MS: Effects of retro-nasal aroma release on satiation. Br J Nutr 2008, 99,1140-8.

17. Bolhuis DP, Lakemond CMM, de Wijk RA, Luning PA, de Graaf K: Both longer oral sensory exposure to and higher intensity of saltiness decrease ad libitum food intake in healthy normal-weight men. Accepted for publication in Journal of Nutrition .

18. Bolhuis DP, Lakemond CMM, de Wijk RA, Luning PA, de Graaf K: Effect of salt intensity in soup on ad libitum intake and on subsequent food choice. Accepted for publication in Appetite.

19. de Wijk RA, Prinz JF, Engelen L: The role of intra-oral manipulation in the perception of sensory attributes. Appetite 2003, 40:1-7.

20. Kobal G, Hummel T: Cerebral chemosensory evoked potentials elicited by chemical stimulation of the human olfactory and respiratory nasal mucosa. Electroencephal Clin Neurophysiol 1988, 71:241-250.

21. Heilmann S, Hummel T: A new method for comparing orthonasal and retronasal olfaction. Behav Neurosci 2004, 118:412-419.

22. Borland: Delphi Scotts Valley, CA, USA: Borland Software Corporation; 2002.

doi:10.1186/2044-7248-1-3

Cite this article as: de Wijk et al.: Food aroma affects bite size. Flavour 2012 1:3.

\section{Submit your next manuscript to BioMed Central and take full advantage of:}

- Convenient online submission

- Thorough peer review

- No space constraints or color figure charges

- Immediate publication on acceptance

- Inclusion in PubMed, CAS, Scopus and Google Scholar

- Research which is freely available for redistribution

Submit your manuscript at www.biomedcentral.com/submit 